\title{
A Influência da Tensão Elétrica na Qualidade da Solda a Arco Submerso em Chapas Finas
}

\author{
Gustavo de Castro Lopes ${ }^{1}$, Matheus Abrão Abdala ${ }^{1}$, Júlio Cezar Pedrosa da Silva ${ }^{1}$ \\ ${ }^{1}$ Instituto Federal de Goiás (IFG) - Câmpus Goiânia \\ Goiânia - GO - Brasil \\ gustavodecastrolopes96@gmail.com, julio.silva@ifg.edu.br
}

\begin{abstract}
This work aims to analyze the quality of the weld between thin plates, by the submerged arc welding process, using different electrical parameters, in order to observe the influence of these parameters during the process, which is used in large scale in the manufacture and maintenance of equipments and structures. For this purpose, the welds were made on thin $6 \mathrm{~mm}$ plates using five different electrical current ranges pre-established; in addition, the welded parts were examined in a non-destructive test by the magnetic particle method so that it was possible to check for possible defects in the weld region. A strong relationship was observed between the electric current working range, the surface quality of the weld and the ease of handling the equipment; lower currents (until 300 A) enabled better handling, also leading to better quality surface of the piece; the more intense currents (400 A or more) were difficult to handle, high penetration and therefore showed clearer weld defects.
\end{abstract}

Resumo. Este trabalho consiste na análise da qualidade da solda entre chapas finas, realizada pelo processo de soldagem a arco submerso, com a utilização de diferentes parâmetros elétricos, com o objetivo de observar a influência desses parâmetros durante o processo, que é utilizado em larga escala na fabricação e manutenção de peças, equipamentos e estruturas. Para isso, foram feitas soldas em chapas finas de $6 \mathrm{~mm}$ utilizando-se cinco diferentes faixas de corrente elétrica pré-estabelecidas; além disso, as peças soldadas foram examinadas em ensaio não-destrutivo pelo método de partícula magnética para que fosse possível verificar os possíveis defeitos na região da solda. Foi observada uma forte relação entre a faixa de corrente elétrica de trabalho, a qualidade superficial da solda e a facilidade de manuseio do equipamento; correntes mais baixas (até $300 \mathrm{~A}$ ) possibilitaram um melhor manuseio, acarretando também uma melhor qualidade superficial da peça; já as correntes mais intensas (400 A ou mais) apresentaram difícil manuseio, alta penetração e, portanto, apresentaram defeitos de solda mais nítidos.

\section{Introdução}

O presente projeto tem como finalidade o desenvolvimento de pesquisa voltada para a área de soldagem a arco submerso, tendo em vista a vasta aplicação do processo e a pouca produção científica do mesmo. Existem alguns processos de soldagem como eletrodo revestido, MIG (Metal Inert Gas), TIG (Tungsten Inert Gas), mas pouco se abordam, tanto nas literaturas quanto em artigos, sobre o processo de arco submerso, apesar de 
o mesmo apresentar maior taxa de deposição de metal que as demais e seus cordões de solda apresentam melhor qualidade superficial. Dos poucos trabalhos relacionados a esse processo, destacam-se [Jorge et al. 2015] que realizou um estudo das propriedades mecânicas e microestruturais de juntas soldadas de aço carbono obtidas pelo processo a arco submerso, visando o aumento da produtividade na fabricação de tubulações para equipamentos de ancoragem. Pode-se destacar também o trabalho de [Pardal et al. 2011], que apresentou os resultados da caracterização e avaliação da resistência à corrosão de uma junta soldada correspondente a uma tubulação de aço inoxidável duplex (AID) UNS S31803 de $35 \mathrm{~mm}$ de espessura de parede soldada pelos processos de soldagem TIG (GTAW) na raiz e arco submerso (SAW) no enchimento e acabamento.

O processo de soldagem a arco submerso é vastamente utilizado em peças de elevada espessura, como por exemplo na construção naval, possuindo um cordão de solda com excelente qualidade superficial [Borba et al. 2015]. Esse fator torna o arco submerso um processo bastante versátil e interessante. Assim, torna-se bastante útil o conhecimento dos parâmetros que afetam a qualidade do cordão de solda, analisando diferentes tensões e correntes de trabalho, ocorrendo uma possível formação de defeitos. Desta forma, foram realizados cordões de solda, utilizando o processo a arco submerso, variando esses parâmetros e posteriormente foi avaliada a qualidade da solda através de ensaio não-destrutivo.

\subsection{Objetivos}

Analisar a qualidade da solda a arco submerso em diferentes faixas de corrente elétrica, aplicada em chapas finas, utilizando-se do ensaio não-destrutivo por partícula magnética. Especificamente, pretende-se:

- Realizar um estudo bibliográfico;

- Efetuar o corte e preparação das chapas para fazer a soldagem;

- Executar a soldagem variando as faixas de corrente elétrica;

- Inspecionar a qualidade das soldas utilizando o ensaio não-destrutivo por partículas magnéticas.

\section{Fundamentação Teórica}

No processo de soldagem por arco submerso, o calor necessário para a fusão do material é gerado por um arco elétrico que é formado entre a peça de trabalho e o final do consumível, no qual ambos estão cobertos por uma camada de fluxo granular. Portanto, o arco fica coberto e escondido, não produzindo radiação visível [Fortes 2004].

Durante a soldagem, o calor produzido pelo arco elétrico funde uma parte do fluxo juntamente com a ponta do eletrodo. A zona de soldagem fica sempre envolta e protegida pelo fluxo escorificante, sobrepondo-se ainda por uma camada de fluxo não fundido. $\mathrm{O}$ eletrodo permanece um pouco acima do metal-base e o arco elétrico se desenvolve nesta posição. Com o deslocamento do eletrodo ao longo da junta, o fluxo fundido separa-se do metal de solda líquida na forma de escória.

O metal de solda possui um ponto de fusão mais elevado que a escória e então solidifica-se enquanto esta ainda permanece fundida, protegendo o metal de solda recém solidificado, que é muito reativo com oxigênio e nitrogênio da atmosfera. Com o resfriamento posterior remove-se o fluxo não fundido, e a escória rapidamente se destaca do 
metal de solda [Wainer et al. 1992]. O esquema básico do funcionamento está ilustrado na Figura 1.

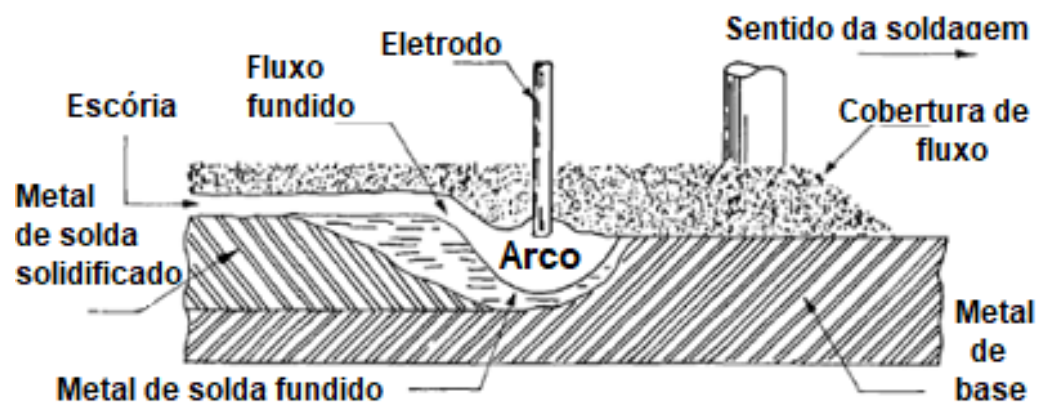

Figura 1. llustração do funcionamento do processo de soldagem com arco submerso. Fonte: Adaptado de [Wainer et al. 1992]

Os eletrodos utilizados no arco submersos são normalmente revestidos de cobre, visando evitar oxidações superficiais durante seu armazenamento. Eles são fabricados em faixas de composição química especificadas e trefiladas até os diâmetros desejados. É um processo que fornece elevado rendimento, pois não há perdas de metal por projeção. Soldas feitas por arco submerso apresentam boa ductilidade e tenacidade ao impacto, além de boa uniformidade e acabamento na aparência dos cordões de solda. As propriedades mecânicas na solda são compatíveis as do metal de base utilizado, além disso o processo possui elevada taxa de deposição.

A soldagem a arco submerso possui como vantagens a elevada velocidade de soldagem; alta taxa de deposição; boa integridade do metal de solda; processo de fácil manuseio sem emissão de faíscas, respingos e fumos; melhor ambiente de trabalho e maior segurança para o soldador; produção de uma boa escória, que protege de impurezas e de fácil retirada. Entretanto possui limitações como a posição de soldagem, possível somente para posição plana e horizontal, e limitação em relação ao tipo de junta, sendo possível trabalhar somente com juntas em linha. A Figura 2 apresenta os componentes básicos do equipamento de soldagem com arco submerso.

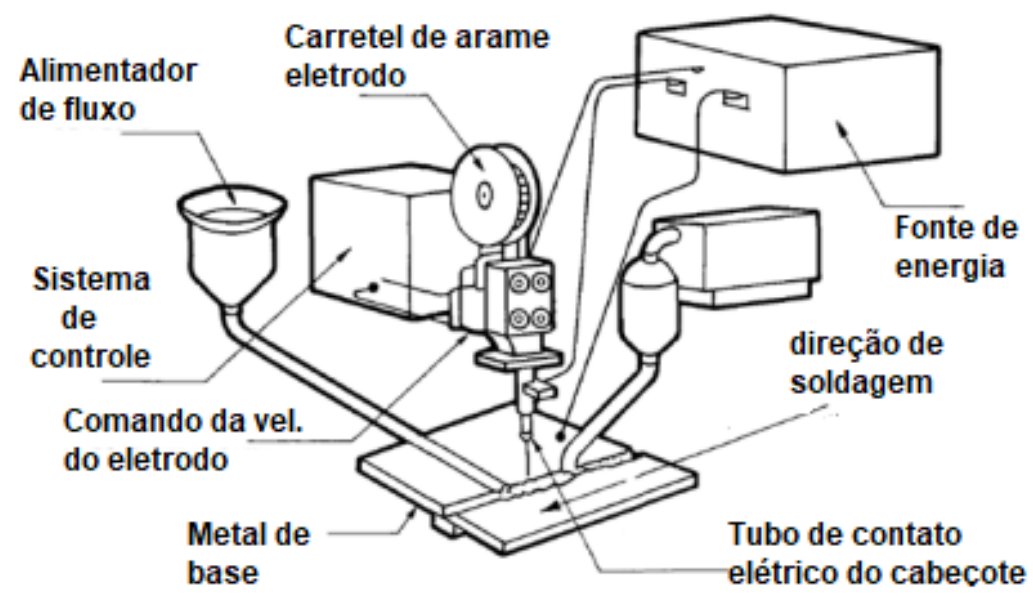

Figura 2. Equipamentos de Soldagem a Arco Submerso. Fonte: Adaptado de [Wainer et al. 1992] 
Para realizar a inspeção da qualidade da solda obtida, realizou-se o ensaio nãodestrutivo por partícula magnética. Esse ensaio consiste em submeter a peça a um campo magnético. As descontinuidades existentes na peça, isto é, os defeitos, irão causar um campo de fuga do fluxo magnético existente na peça. As partículas magnéticas serão atraídas, devido ao surgimento de polos magnéticos e ficarão aglomeradas na região que houver uma descontinuidade. A aglomeração indicará o contorno do campo de fuga, fornecendo a visualização do formato e da extensão do defeito presente [Andreucci 2009].

\section{Metodologia}

Para a realização desse trabalho, foram utilizados os seguintes materiais e equipamentos:

- Chapa de aço com espessura de $6 \mathrm{~mm}$;

- Máquina de soldagem a arco submerso;

- Equipamento para o ensaio de partícula magnética;

- Equipamento para o ensaio de líquido penetrante.

Primeiramente realizou-se uma sequência de testes na máquina de soldagem a arco submerso (Figura 3) para definição exata dos parâmetros (corrente elétrica e tensão). Em seguida, foram selecionadas algumas chapas de espessura de $6 \mathrm{~mm}$ e depois utilizou-se uma serra alternativa para cortá-las pela metade, obtendo chapas de comprimento menores, conforme Figura 4. Posteriormente, partiu-se para a soldagem a arco submerso.

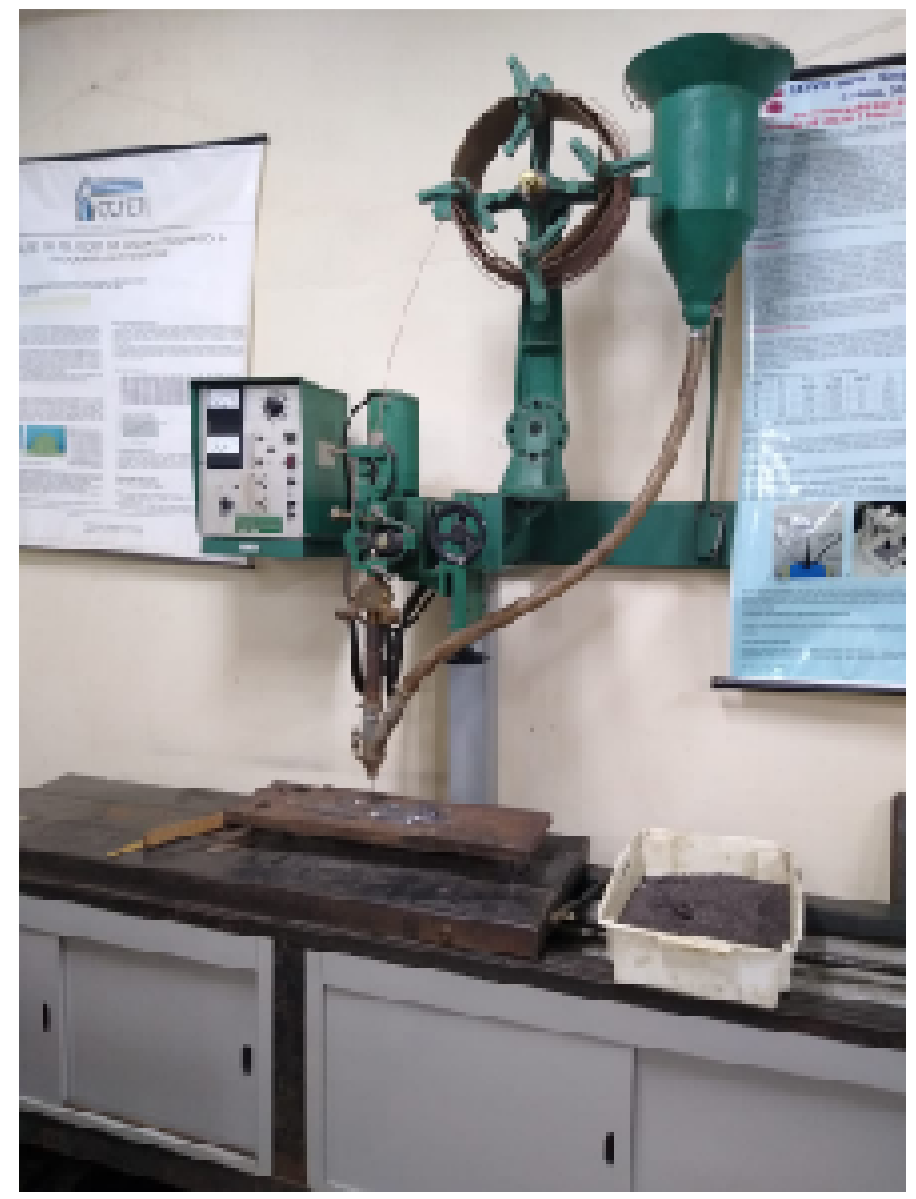

Figura 3. Máquina de soldagem a arco submerso 


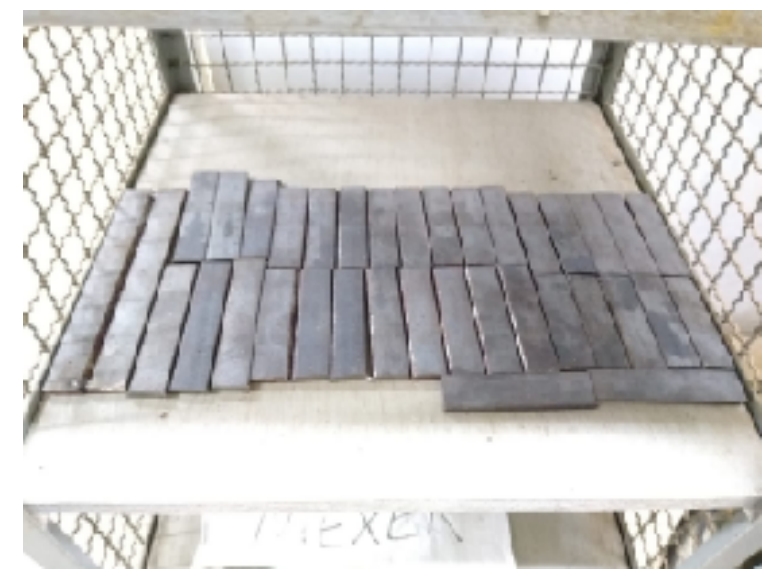

Figura 4. Chapas de $6 \mathrm{~mm}$ para realizar a soldagem

O processo de soldagem foi realizado utilizando um único carretel de arame como eletrodo, entretanto variou-se a corrente de trabalho na faixa de $200 \mathrm{~A}$ a $600 \mathrm{~A}$. O avanço da mesa foi feito de forma manual através da manivela, contudo a velocidade de avanço foi mantida constante para todos os cordões de solda. Em seguida, os cordões de solda foram analisados utilizando-se o ensaio não-destrutivo de partícula magnética.

Para realizar o ensaio de partícula magnética, selecionaram-se o equipamento e as peças com os cordões de solda. Em seguida, para cada chapa, aplicou-se o fluido com as partículas magnéticas no cordão de solda e então utilizou-se o um aparelho para magnetizar a chapa. Por fim, utilizou-se uma luz negra para visualizar as descontinuidades presentes em cada peça e então registrou-se por foto o resultado realizado em cada peça.

\section{Resultados}

A partir da sequência de testes realizada na máquina de soldagem a arco submerso, foi possível obter um melhor controle nos parâmetros elétricos do equipamento, conforme Tabela 1.

Tabela 1. Parâmetros Elétricos do Equipamento para Soldagem a Arco Submerso

\begin{tabular}{|c|c|c|}
\hline Potenciômetro [\%] & Corrente [A] & Tensão [V] \\
\hline 26 & 200 & 40 \\
\hline 40 & 300 & 38 \\
\hline 52 & 400 & 34 \\
\hline 70 & 500 & 32 \\
\hline$>80$ & 600 & 32 \\
\hline
\end{tabular}

De acordo com a metodologia aplicada, foi possível realizar o processo de soldagem na faixa de corrente desejada, conforme ilustram as Figuras 5 a 9. Na Figura 5, pode se observar que houve uma soldagem contínua; no entanto, nem toda a peça apresentou penetração completa, se manifestando apenas no final da peça. Esse perfil de solda pode apresentar alguns problemas quando a peça for submetida a ensaios de tração ou outro esforço mecânico. Em síntese, pode ser inferido que, mesmo para essa pequena espessura, é inviável a utilização da soldagem a arco submerso nessas condições. 


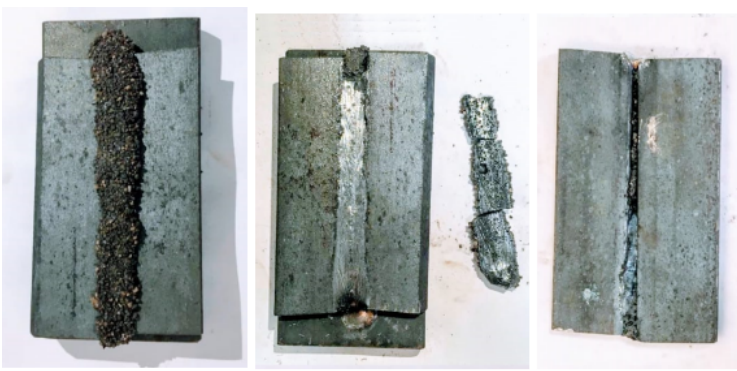

Figura 5. Soldagem na chapa a 200 A (com escória; sem escória; fundo da peça)

A Figura 6 mostra a soldagem realizada com uma corrente de 300 A. Não houve uma penetração total nas amostras realizadas a essas condições, no entanto, o cordão apresentou um aspecto visual extremamente interessante: é possível verificar que não existem bolhas superficiais na peça; ter uma escória cheia de bolhas, mas exibindo um cordão perfeitamente executado, sem nenhum defeito nítido, proporciona um aspecto visual muito positivo e uniforme. Esse cordão apresenta uma melhora com relação ao anterior, em termos de continuidade e de homogeneidade, seja visual, superficial ou mesmo de penetração nas amostras.

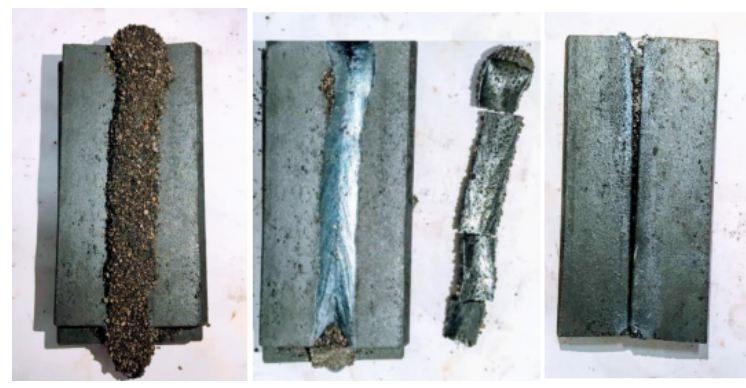

Figura 6. Soldagem na chapa a 300 A (com escória; sem escória; fundo da peça)

A Figura 7 apresenta a soldagem realizada com corrente de 400 A. Nesta etapa, observou-se uma descontinuidade mais nítida do cordão. Apesar de ter-se obtido uma penetração quase completa, o aspecto do cordão é visivelmente descontínuo, deslocado, até malfeito; essa descontinuidade se deu, em parte, pois a peça se moveu um pouco sobre a mesa, em função da alta taxa de energia envolvida no processo. Contudo, verificouse uma peça mais heterogênea que as anteriores, mas com defeitos superficiais e de penetração.

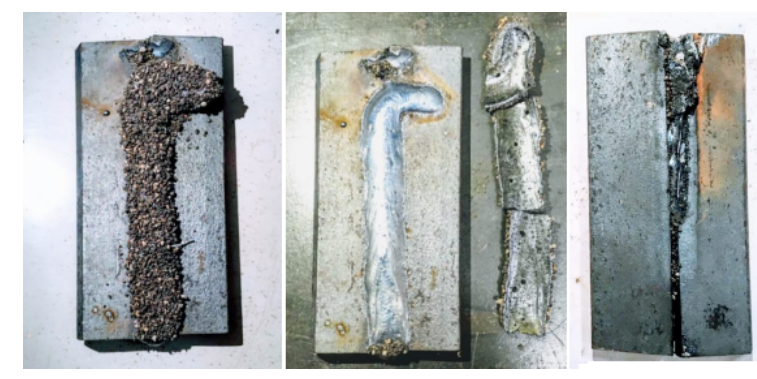

Figura 7. Soldagem na chapa a 400 A (com escória; sem escória; fundo da peça) 
A Figura 8 exibe a soldagem realizada com corrente de 500 A. Essa etapa apresentou a pior qualidade de solda entre todas as realizadas. É visível que em todos os testes realizados nessas condições há uma grande descontinuidade no processo, o que vai contra qualquer definição de soldagem, assim como qualquer possível aplicação de uma peça nessas condições, sejam elas ornamentais ou estruturais. Portanto, conclui-se que, nessas condições, a soldagem de uma chapa fina se torna completamente inviável e indesejável; houve uma completa penetração visual, mas esta não compensa a falta de homogeneidade apresentada ao longo do cordão de solda

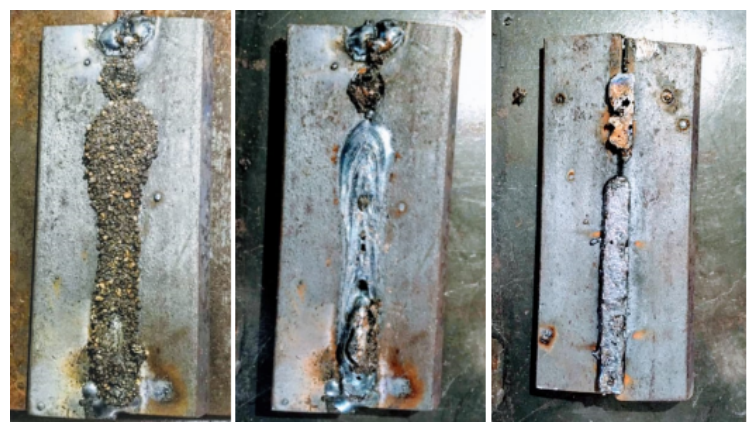

Figura 8. Soldagem na chapa a 500 A (com escória; sem escória; fundo da peça)

A Figura 9 apresenta uma das amostras para condição de corrente de 600 A. Embora a peça se apresente visualmente melhor que a anterior, a peça também apresenta heterogeneidade visual muito acentuada, com presença de grandes bolhas na parte inferior da peça, uma grande descontinuidade do cordão sendo interrompido nas extremidades de forma natural porém desordeira, uma penetração completa porém que não parece acrescentar muito a peça além de deformações.

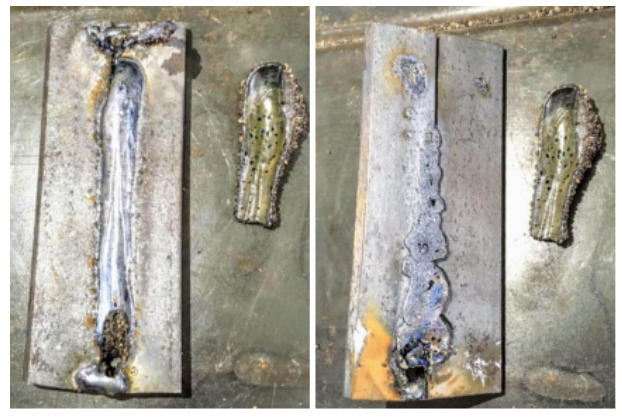

Figura 9. Soldagem na chapa a 600 A (sem escória; fundo da peça)

Após a análise visual, percebe-se que os cordões realizados a 300 A apresentam maior qualidade que os demais; no entanto, para uma verificação mais completa, foi realizado um ensaio não-destrutivo em cada uma das peças, que visa exibir os defeitos internos ao cordão de solda. Os resultados obtidos são mostrados em seguida, a partir do ensaio de partícula magnética, conforme as Figuras 10 a 14.

Na Figura 10 vemos que foi formada uma pequena região de mordedura, um defeito que costuma ser ocasionado pela alta energia utilizada em uma peça de espessura muito pequena. Algumas bolhas podem ser vistas, assim como uma trinca na parte inferior, bem discreta. Com o ensaio de partícula magnética pode-se observar que, apesar dos citados, não há grandes defeitos na peça, superficiais ou subsuperficiais. 


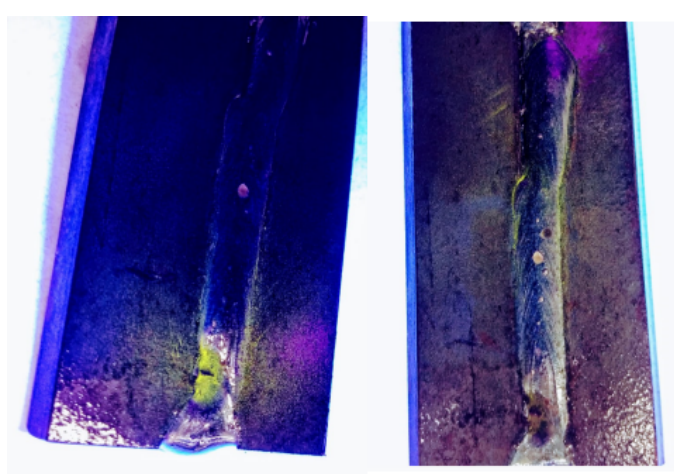

Figura 10. Ensaio por partícula magnética nas chapas a $200 \mathrm{~A}$

Na Figura 11 percebe-se o aumento das mordeduras nas laterais dos cordões de solda, além do aumento considerável da zona termicamente afetada; ambos ocorridos já eram esperados, devido ao aumento da corrente, e, consequentemente, da energia de soldagem. A peça da direita apresenta uma região central mais funda e com menos reforço que o restante da peça, além da presença de uma trinca. A solda feita a $400 \mathrm{~A}$, exibida abaixo na Figura 12, apresentou poucos defeitos, sendo bem superior às demais. Conforme esperado, a peça apresentou mais mordeduras que as anteriores e um aumento da zona termicamente afetada. Também foi observada uma série de bolhas que, apesar de pouco expressivas, são uma falha em larga escala, além de observar-se reforço reduzido no final do cordão de solda. A peça apresenta heterogeneidade visual, porém não apresenta trinca visual certeira, como nos casos anteriores.

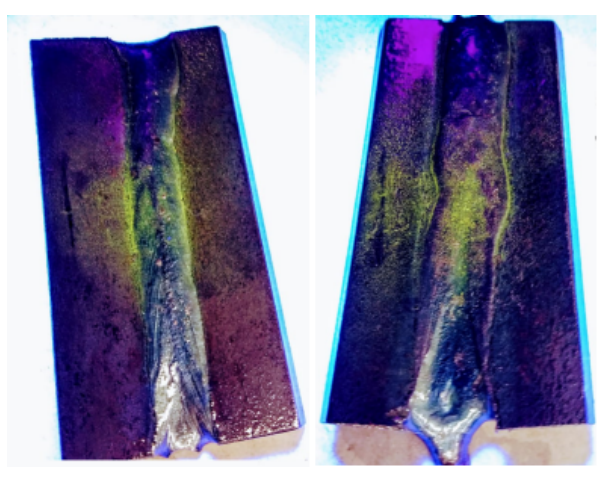

Figura 11. Ensaio por partícula magnética nas chapas a $300 \mathrm{~A}$

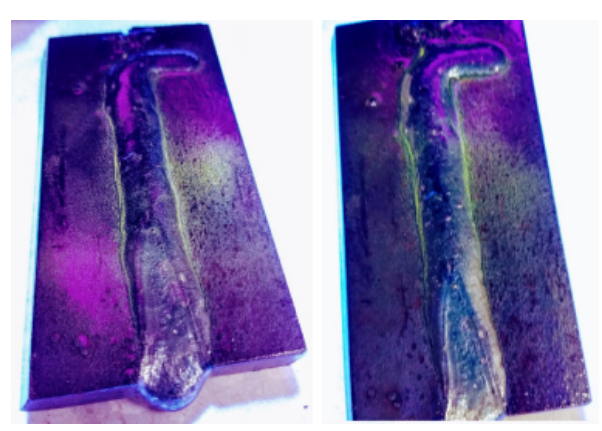

Figura 12. Ensaio por partícula magnética nas chapas a $400 \mathrm{~A}$ 
As Figuras 13 e 14 apresentam os resultados para as soldagens de 500 A e 600 A, respectivamente; estas etapas apresentaram condições bem parecidas de soldagem, e isso se refletiu nos resultados, também bem semelhantes.

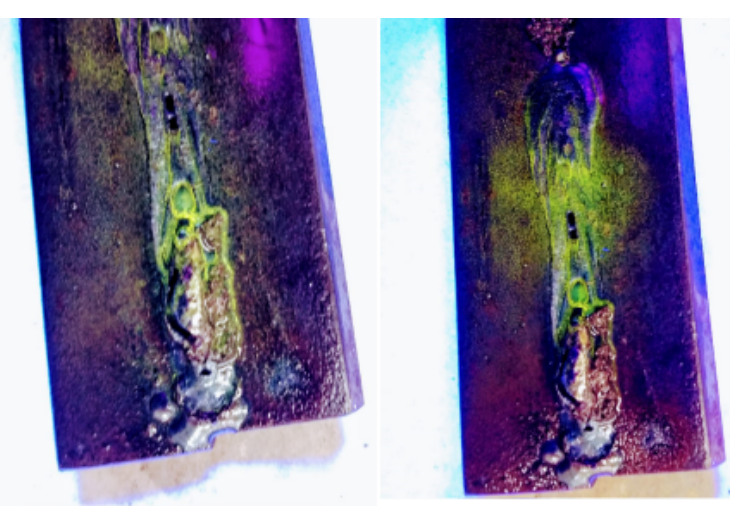

Figura 13. Ensaio por partícula magnética nas chapas a $500 \mathrm{~A}$

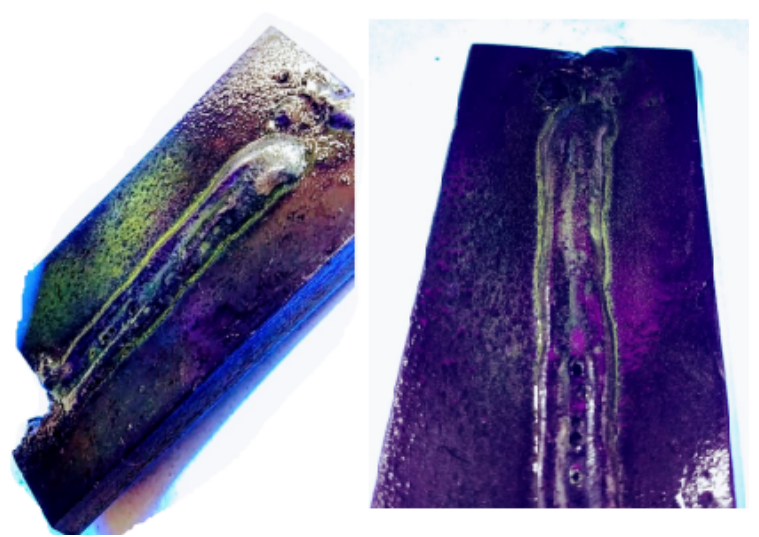

Figura 14. Ensaio por partícula magnética nas chapas a $600 \mathrm{~A}$

Como pode ser visto nas Figuras 13 e 14, as duas condições de soldagem geraram peças com grandes defeitos estruturais, como misturas bastante significativas e zonas termicamente afetadas que englobam quase toda a peça. Ambas apresentaram também poros bastante consideráveis, assim como trincas ao longo da peça.

Essas últimas condições apresentam descontinuidades sérias para a soldagem, o que as torna, indesejáveis e completamente inviáveis, além de proporcionarem uma perfuração na chapa, que só não foi mais continua e acentuada devido a existência de cobre-junta, que permitiu continuidade sem perfuração da peça. No entanto, deve-se salientar que, a partir de $400 \mathrm{~A}$, mostrou-se uma grande dificuldade de realizar a solda, grudando-se a peça na cobre-junta, que só saiu com aplicação de força manual bem ríspida e agressiva, auxiliada por ferramentas.

\section{Conclusão}

Observou-se que na soldagem a arco submerso a qualidade superficial do cordão de solda depende da faixa de corrente de trabalho. As soldas realizadas com corrente elétrica até 300 A resultaram em melhor facilidade de operação do processo, além de qualidade 
superficial superior em relação a correntes maiores (400 A a 600 A). Ademais, não houve penetração total nos procedimentos realizados com as correntes de $200 \mathrm{~A}$ e $300 \mathrm{~A}$.

As peças tratadas nessas faixas de corrente apresentaram trincas e mordeduras, além de alta presença da zona termicamente afetada; também foi observada uma falta de reforço em alguns pontos do cordão, além da presença de bolhas. Entretanto, não foram observados defeitos tão sérios, como era de se esperar inicialmente para uma soldagem a arco submerso em chapas de espessura tão pequena.

O processo de soldagem foi mais difícil em correntes a partir de $400 \mathrm{~A}$, as chapas sofriam um impacto inicial da abertura do arco e deslocavam-se durante a soldagem, prejudicando a continuidade do processo, a qualidade superficial do cordão de solda e comprometendo a posição do cordão de solda. Além disso, iniciou-se, nessa faixa de corrente, a penetração total da solda em partes do cordão, chegando em alguns casos a perfurar parte da chapa, como ocorreu no procedimento realizado a $600 \mathrm{~A}$.

\section{Referências}

Andreucci, R. (2009). Ensaio por partículas magnéticas. Editora Associação Brasileira De Ensaios Não Destrutivos e Inspeção. São Paulo.

Borba, T. M. D., Flores, W. D., Turani, L. d. O., and Cardoso Junior, R. (2015). Avaliação da soldabilidade do aço naval eh36 tmcp soldado por arco submerso com elevado aporte de calor. Soldagem \& Inspeção, 20(1):92-104.

Fortes, C. (2004). ESAB - Processos de Soldagem: Arco Submerso. Disponível em: https://www.esab.com.br.

Jorge, J. C. F., Souza, L. F. G. d., Marouco, E. d. S., Santos Filho, O. R. d., and Diniz, J. L. C. (2015). Propriedades mecânicas e microestruturais de juntas soldadas pelo processo a arco submerso com elevado aporte térmico. Soldagem \& Inspeção, 20(3):347-358.

Pardal, J. M., Souza, G. C. d., Tavares, S. S. M., Fonseca, M. d. P. C., Ferreira, M. L. R., Martins, L. M., and Samra Filho, O. A. (2011). Caracterização e avaliação da resistência à corrosão na soldagem de tubulação de aço inoxidável duplex uns s31803 pelo processo a arco submerso. Soldagem \& Inspeção, 16(4):310-321.

Wainer, E., Brandi, S. D., and de Mello, F. D. H. (1992). Soldagem: processos e metalurgia. Editora Blucher. 